\title{
Skeletal Muscle Cell Damage Indicators in Volleyball Players after the Competitive Phase of the Annual Training Cycle
}

\author{
by \\ Mateusz Radojewski ${ }^{1}$, Tomasz Podgórski ${ }^{1}$, Barbara Pospieszna², Jakub Kryściak', \\ Ewa Śliwicka', Joanna Karolkiewicz ${ }^{1}$
}

\begin{abstract}
The aim of the study was to evaluate the impact of the competitive phase on physiological and metabolic indices and selected markers of skeletal muscle damage in male volleyball players. The study group consisted of 24 young male volleyball players. During the study, participants underwent two series of measurements, before and after the competitive phase of the annual training cycle. In both study terms, players performed an incremental treadmill running test to determine their ventilatory threshold and maximal oxygen uptake. Venous and capillary blood samples were taken for biochemical analysis. There was no significant difference in the physical fitness level, values of biochemical variables and the level of antioxidant status in the surveyed athletes between the two study terms. Significant changes within skeletal muscle damage markers were observed between the beginning and the end of the competitive period: an increase in the concentration of cellular DNA damage products (8-hydroxy-2'-deoxyguanosine; $p<0.0001)$ and a decrease in muscle activity of creatine kinase $(p<0.05)$. In spite of the increment in cell damage markers, the unaffected level of physiological and biochemical markers may indicate that the experienced cell destruction did not negatively affect the level of physical fitness. When designing the annual training plan, coaches and athletes need to take into consideration that temporary physiological states - oxidative stress and inflammation - may be required to attain training adaptation.
\end{abstract}

Key words: training, team sports, injury, prevention, biochemical variables.

\section{Introduction}

Volleyball is a complex sport with technical, tactical and fitness demands (GonzálezRavé et al., 2011; Manna et al., 2011; Sheppard and Cowan, 2011; Lehnert et al., 2017). Serve, reception, set, attack and block are typical game actions that are decisive aspects of winning or losing in international competitions. Success in volleyball, like in all sports, is largely obtained by the means of a properly established training process consisting of training cycles divided into periods, sub-periods and training units. Wellplanned training loads, depending on the type of training and the period of the annual training cycle, lead to favorable changes in morphological, biochemical and physiological characteristics of the players. To warrant an increase in athletes' performance, the choice of training loads must always be adjusted to a player's individual adaptive ability (Cieśla et al., 2015).

The most important goal for the competitive phase is to create optimal conditions to obtain and stabilize players' physical performance. In the Polish national volleyball leagues, the competitive phase lasts about 20 weeks, and training loads applied during this period are focused primarily on improving specific physical fitness as well as technique and tactics of the game. During the game, volleyball

\footnotetext{
1 - Department of Biomedical Foundations of Physical Activity, University School of Physical Education in Poznań, Poland.
}

2 - Department of Tourism and Recreation, Adam Mickiewicz University in Poznań, Poland. 
players perform short bouts of very high intensity physical effort (action time lasts approximately 11s), with relatively short recovery periods (average rest time is $14 \mathrm{~s}$ ) (Polglaze and Dawson, 1992; Sheppard et al., 2007). Frequently repeated sprints, dives and jumps place considerable demands on the muscular system (Sheppard et al., 2007). Many of these game actions are dominated by eccentric muscle contractions (Brown et al., 1999). For instance, to resist the impact of landing, the knee extensor muscles perform an eccentric action that involves a counter-extension movement to absorb kinetic energy (Devita and Skelly, 1992). It seems probable that following numerous jumps (around 20 per set for blockers and spikers) those repetitive eccentric muscle actions may cause muscle damage to the knee extensors (Miyama and Nosaka, 2004; Polglaze and Dawson, 1992).

Exercise-induced muscle damage involves complex interactions of events, which seem to include muscle rupture due to myofibril injury (rupture of myofibrils), impaired excitationcontraction coupling associated with local ATP depletion, changes in the intracellular calcium homeostasis, oxidative stress and inflammation (Nikolaidis et al., 2008). On the other hand, accumulation of reactive oxygen and nitrogen species (RONS), and cytokines stimulate changes in cell signaling and gene expression, which may contribute to adaptive responses to contractile activity, including changes in stress protein expression and upregulation of some cytoskeletal proteins, antioxidant enzymes, DNA repair proteins, and mitochondrial electron transport proteins (Souglis et al., 2015).

Thus, exercise-induced free radical compounds, along with pro- and antiinflammatory cytokines, are crucial during regular training. They enable the metabolic changes to occur, in order to adapt athletes to higher training loads and competition. However, it is necessary to avoid exceeding the safe injury level. Exercise-induced mechanical and metabolic micro-tears in the muscle, not compensated by appropriate recovery, can result in a higher risk of injury or overtraining, a long-term reduction in exercise capacity and a decrease in physical performance (Smith, 2000).

Australian national team volleyball players, during international seasons, on average perform 9-13 training sessions per week, with 1540 games played per season (Sheppard and Cowan, 2011). In the Polish professional league volleyball players spend approximately 800 hours per year playing volleyball and improving physical fitness (Cieśla et al., 2015). The magnitude of training loads applied during competition and training (often on consecutive days) and thus shortened time for recovery, may accelerate athletes' fatigue, which then increases the probability of injury (Cieśla et al., 2015; Ferretti and Zeppilli, 2003). However, adaptation to training loads, gained with training experience, enables a shorter time of recovery. Ferretti and Zeppilli (2003) reported that players from clubs competing in levels lower than the top league were more vulnerable to cellular damage and thus had more injuries than players at a higher level of competition.

The majority of researchers tend to assume that the most essential reasons for influencing and modifying the athletes' metabolism while training are the oxidative damage and the proinflammatory cytokines produced, among others, in damaged muscle fibers (Witek, 2009). Thus, an additional assessment of changes in the level of intracellular damage and antioxidant capacity caused by strenuous workouts and competition can significantly enhance knowledge, which in turn can lead to increased efficiency of the players.

Therefore, the aim of this study was to evaluate the impact of the competitive phase on physiological and metabolic changes as well as selected markers of skeletal muscle damage in male volleyball players. Our hypothesis was that: 1) intensive training loads during the main competitive phase would cause skeletal muscle damage in male volleyball players; and that 2) the physical capacity of players would increase after the competitive phase of the annual training cycle.

\section{Methods}

The study group consisted of 24 male volleyball players (mean age: 22 years and 5 months $( \pm 3.06)$; mean training experience: 7 years and 4 months $( \pm 4.06))$, competing in primary and third leagues in Poland. The players were recruited from the Polish league teams. The inclusion criteria were at least 3 years of training experience and good health status, constant 
participation in practice sessions since the beginning of the analyzed season, without injuries and inflammation lasting longer than 3 days. Before providing written consent, all participants were precisely instructed about the protocol of the study. All procedures were approved by the ethics committee at the Poznan University of Medical Sciences.

The main features of weekly training loads in both leagues are shown in Table 1 . Players from the $1^{\text {st }}$ league, during the competitive phase of the 2012/2013 season, performed at least seven training units per week: two power training sessions and five specific volleyball sessions in the gym. Matches during the competitive phase were held once a week, mainly on Saturdays (22 competitions per season). The players from the $3^{\text {rd }}$ league, during the competitive phase of the same 2012/2013 season, performed at least five training units per week: one power training session and four specific volleyball sessions in the gym. Matches were held also once a week, but there were only 14 competitions per season. In both teams, a training unit lasted approximately $2 \mathrm{~h}$.

Within a typical training session in the gym, three parts could be distinguished. The introductory part comprised a warm-up, stationary exercises and stretching, short runs and block jumps, as well as passing the ball with a coplayer. The main part included improvement of technical, tactical and game skills. The cool-down consisted of light jogging, stretching and discussion about training and tactics.

During the study, all participants underwent two series of measurements, before and after the competitive phase of the annual training cycle, designated term I and term II respectively. In both study terms, the anthropometric measurements (body mass and body height) were taken and body composition was assessed by the bioimpedance method, using the analyzer Bodystat ${ }^{\circledR} 1500$ (Bodystat Ltd., UK).

At the beginning and at the end of the study period, all players were subjected to a ventilatory threshold and maximal oxygen uptake test in the Exercise Physiology Laboratory of the Poznań University of Physical Education.

After a light standardized breakfast (approximately $200 \mathrm{kcal}$ ), participants performed a maximal incremental exercise test on a treadmill (Katana Sport 30, Lode, Netherlands). The initial 3 min at a speed of $8 \mathrm{~km} \cdot \mathrm{h}^{-1}$ were treated as a warmup. After that, the workload was gradually increased by $0.7 \mathrm{~km} \cdot \mathrm{h}^{-1}$ every minute, until maximal oxygen uptake $\left(\mathrm{VO}_{2 \max }\right)$ was reached. During the test, with the use of portable breathby-breath gas analyzer Oxycon Mobile (Jeager, Germany) and Sport Tester (s610i, Polar, Finland), cardiorespiratory variables were continuously recorded: minute lung ventilation, $\mathrm{CO}_{2}$ excess, actual $\mathrm{O}_{2}$ intake, respiratory exchange ratio (VE, $\mathrm{VCO}_{2}, \mathrm{VO}_{2}, \mathrm{RER}$ ) and heart rate (HR). The level of athletes' anaerobic threshold was based on the ratio of $\mathrm{VCO}_{2}$ to $\mathrm{VO}_{2}$ (RER) changes and a nonlinear, rapid increase in $\mathrm{VE}$, which corresponded to the ventilatory threshold (VT).

On a day prior to the tests, players were asked to avoid exercise as well as alcohol and caffeine intake. In both study terms, before and three minutes after completing the exercise test, $200 \mu \mathrm{l}$ of capillary blood was taken from the fingertip, in which lactate concentration and acidbase balance variables were measured using the spectrophotometric method (Synergy 2 SIAFRT, BioTek, USA) and a blood gasometric analyzer, Cobas b121 (Roche, Switzerland), respectively (Maughan, 1982).

After an overnight fast, between 7 and 8 a.m., in both terms of the study, venous blood samples (basilic vein) were taken. Serum, plasma and red blood cell hemolyzate samples were stored at $-80^{\circ} \mathrm{C}$ until biochemical analysis.

In plasma samples, bloods' total antioxidant capacity (TAC), the concentration of 8-iso-prostaglandyn F2 $\alpha$ (8-iso-PGF2 $\alpha$ ) and thiobarbituric acid reactive substances (TBARS) were measured using tests made by CELL BIOLABS, Inc. (USA). The TAC Assay Kit was based on the reduction of copper (II) to copper (I) by antioxidants [reducing equivalents (CRE)]. In the serum samples, concentrations of cellular DNA damage products (8-hydroxy-2'deoxyguanosine) were measured with commercially available ELISA immunoassays, CELL BIOLABS, Inc. (USA), while the activity of creatine kinase type $M(C K-M)$ was measured using CUSABIO (China) tests.

All data are expressed as mean $\pm \mathrm{SD}$. The STATISTICA software package (version 10.1, StatSoft, Inc., USA) for MS Windows was used. Obtained data violated normality and demonstrated heterogeneous variability, therefore 
Table 2

Basic characteristics of studied volleyball players before and after the competitive phase of the annual training cycle

\begin{tabular}{|c|c|c|c|}
\hline & $\begin{array}{l}\text { I term } \\
\overline{\mathbf{x}} \pm \mathrm{SD}\end{array}$ & $\begin{array}{l}\text { II term } \\
\overline{\mathbf{x}} \pm S D\end{array}$ & $\begin{array}{c}\text { Wilcoxon } \\
\text { Test } \\
p\end{array}$ \\
\hline Body height $(\mathrm{cm})$ & $193.4 \pm 7.6$ & & \\
\hline Body mass (kg) & $87.8 \pm 7.0$ & $87.5 \pm 6.3$ & NS \\
\hline BMI $\left(\mathrm{kg} / \mathrm{m}^{2}\right)$ & $23.5 \pm 2.1$ & $23.3 \pm 1.6$ & NS \\
\hline Fat body mass (\%) & $16.1 \pm 3.6$ & $15.6 \pm 2.7$ & $p<0.05$ \\
\hline Lean body mass (\%) & $83.9 \pm 3.6$ & $84.4 \pm 2.7$ & $p<0.05$ \\
\hline
\end{tabular}

NS - non-significant, SD - standard deviation

Table 3

Comparative analysis of the volleyball players' physiological parameters: mean values $( \pm S D)$ estimated during the exercise tests performed before and after the start of the main competitive phase of the annual training cycle

\begin{tabular}{|c|c|c|c|}
\hline & $\begin{array}{l}\text { I term } \\
\overline{\mathbf{x}} \pm S D\end{array}$ & $\begin{array}{l}\text { II term } \\
\overline{\mathbf{x}} \pm S \mathrm{SD}\end{array}$ & $\begin{array}{c}\text { Wilcoxon Test } \\
p\end{array}$ \\
\hline Threshold load $\left(\mathrm{km}^{\prime} \mathrm{h}^{-1}\right)$ & $12.6 \pm 0.6$ & $12.5 \pm 1.1$ & NS \\
\hline Maximal load $\left(\mathrm{km} \cdot \mathrm{h}^{-1}\right)$ & $14.8 \pm 0.73$ & $15.1 \pm 1.1$ & 0.0597 \\
\hline HR at threshold (beats' $\min ^{-1}$ ) & $173.3 \pm 9.3$ & $172.3 \pm 7.3$ & NS \\
\hline HRmax (beats'min' ${ }^{-1}$ ) & $187.3 \pm 6.7$ & $187.5 \pm 6.5$ & NS \\
\hline Threshold time (s) & $575.0 \pm 55.2$ & $562.9 \pm 100.4$ & NS \\
\hline Maximal effort time (s) & $778.1 \pm 68.6$ & $784.5 \pm 90.6$ & NS \\
\hline $\mathrm{VO}_{2 \max }\left(\mathrm{ml} \cdot \mathrm{kg}^{-1} \cdot \mathrm{min}^{-1}\right)$ & $52.4 \pm 3.5$ & $52.7 \pm 3.6$ & NS \\
\hline
\end{tabular}

NS - not significant, $S D$ - standard deviation 


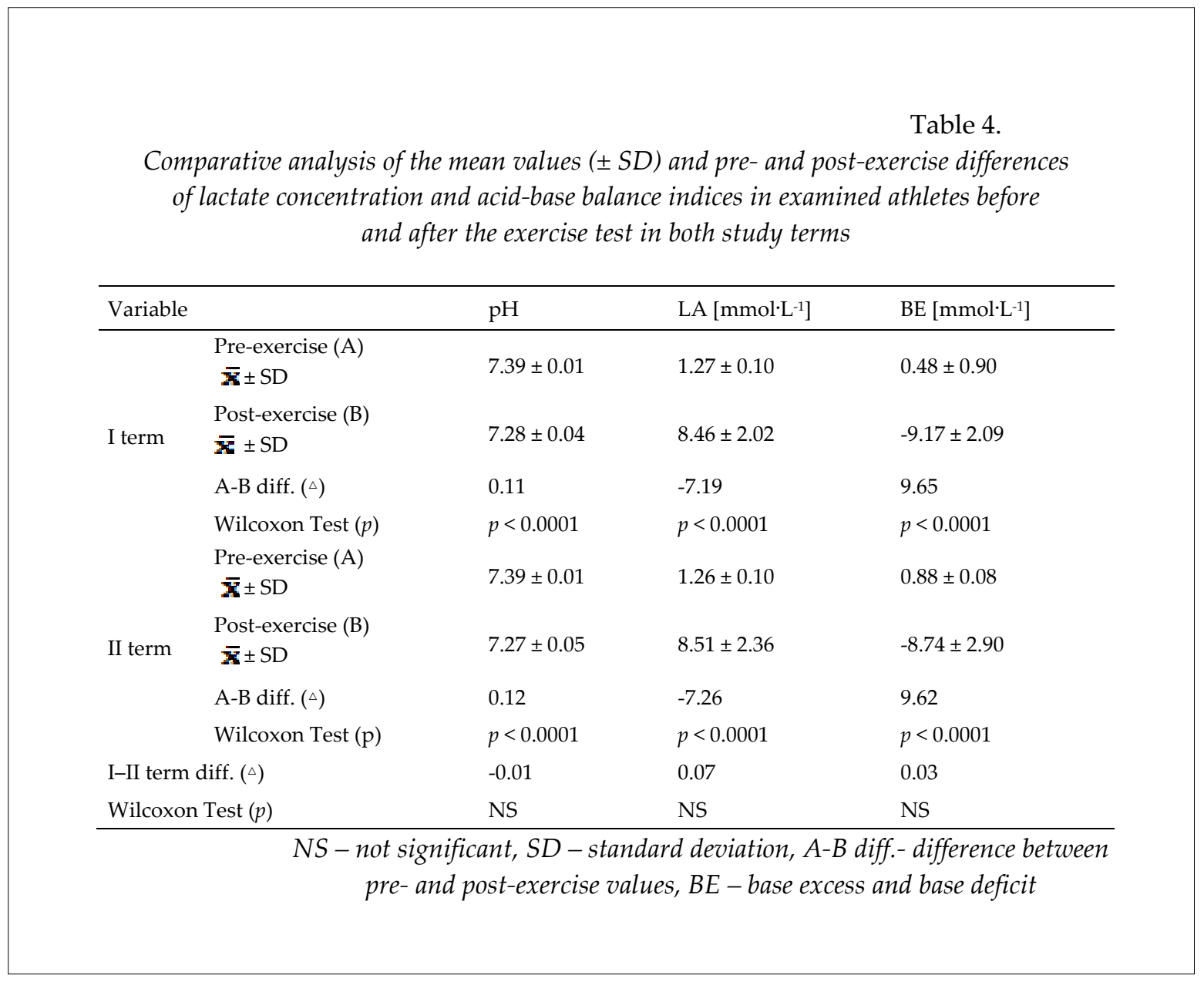

\begin{tabular}{|c|c|c|c|}
\hline \multicolumn{4}{|c|}{$\begin{array}{l}\text { Table } 5 \\
\text { Comparative analysis of the mean resting values }( \pm S D) \text { of antioxidant capacity } \\
\text { and selected markers of skeletal muscle damage in volleyball players before } \\
\text { and after the competitive phase of the annual training cycle }\end{array}$} \\
\hline & $\begin{array}{l}\text { I term } \\
\overline{\mathbf{x}} \pm S D\end{array}$ & $\begin{array}{l}\text { II term } \\
\overline{\mathbf{x}} \pm S \mathrm{DD}\end{array}$ & $\begin{array}{c}\text { Wilcoxon Test } \\
p\end{array}$ \\
\hline TAC (mmolCRE $\left.\cdot \mathrm{L}^{-1}\right)$ & $1.43 \pm 0.38$ & $1.30 \pm 0.34$ & NS \\
\hline $\begin{array}{l}\text { 8-hydroxy-2'-deoxyguanosine } \\
\left(\text { ng } \cdot \mathrm{mL}^{-1}\right)\end{array}$ & $5.42 \pm 1.97$ & $8.64 \pm 1.79$ & $p<0.0001$ \\
\hline 8-iso-PGF2 $\alpha\left(\mathrm{pg} \cdot \mathrm{mL}^{-1}\right)$ & $19.25 \pm 2.35$ & $30.95 \pm 5.28$ & $p<0.05$ \\
\hline TBARS $\left(\mathrm{mmol} \cdot \mathrm{L}^{-1}\right)$ & $2.68 \pm 0.81$ & $2.52 \pm 0.63$ & NS \\
\hline CK-M $\left(\mu \mathrm{U} \cdot \mathrm{mL}^{-1}\right)$ & $56.08 \pm 8.7$ & $50.97 \pm 6.98$ & $p<0.05$ \\
\hline \multicolumn{4}{|c|}{$\begin{array}{c}\text { NS - not significant, } S D \text { - standard deviation, TAC-total antioxidant capacity, } \\
\text { TBARS - thiobarbituric acid reactive substances, } 8 \text {-iso-PGF2 } \alpha-8 \text {-iso-prostaglandyn } F 2 \alpha, \\
C K-M-\text { creatine kinase type } M\end{array}$} \\
\hline
\end{tabular}




\section{Discussion}

In volleyball, each competitive period consists of conditioning, scrimmages and League or national games. These elements should not only improve players' skills, but also increase their exercise tolerance and adaptation to higher training and match loads. However, excessive training loads throughout the long-lasting competitive phase threaten development of serious fatigue, muscle damage or other injuries which in a longer perspective may reduce athletes' physical fitness.

Between the beginning and the end of the competitive phase of the annual training cycle we did not observe any decrement in the level of physical fitness, as well as no significant change in antioxidant status or biochemical variables in surveyed athletes. After the analyzed period there was a significant increase in cell damage indicators, but all the obtained values were within the range of the reference values.

Body composition of studied volleyball players over 20 weeks of the competitive phase of the annual training cycle improved marginally. We observed a significant increase in lean body mass along with a concurrent decrease in fat mass, with no influence on athletes' total body mass (Table 2). Similar findings were noted in female volleyball players after 24 weeks of supervised training (González-Ravé et al., 2011; Manna at al., 2011). Such body composition changes are favorable for maintaining or even improving strength, during the competitive phase.

Maximal aerobic capacity as well as anaerobic threshold indices were stable throughout the competitive phase (Tables 3 and 4). The levels of physical capacity, both before and after the competitive phase of the annual training cycle, were similar to the results of other studies evaluating volleyball players at a similar level of competition (Ferretti and Zeppilli, 2003; Rankovic et al., 2010; Smith et al., 1992). A noted trend in term II towards increased loads $(p=0.0597)$ is most likely a sign of higher exercise tolerance of players at the end of the competitive phase, which consecutively evidences a proper level of preparation for its long duration. Changes of acidbase balance variables and lactate concentration were significant only between pre-test and posttest blood collections in both study terms (Table
4). Yet, their values, like other physical capacity indices, did not differ significantly between terms I and II. A similar level of lactate and acid-base imbalance after the maximal treadmill test in the beginning and at the end of the competitive phase of the annual training cycle positively verified the level of players' physical tolerance (Podgórski et al., 2015).

The average exercise intensity in volleyball practice and games is moderate as most of the physical load derives from the frequently repeated jumps (Polglaze and Dawson, 1992; Smith et al., 1992). All rapid intensive movements, but essentially the eccentric muscle contractions during the landing phase of many jumps, contribute to muscle damage and inflammation in volleyball players (Miyama and Nosaka, 2004; Souglis et al., 2015). There are many indices suggesting the muscle damage occurrence used in sports medicine and diagnostics (Córdova et al., 2010; Obmiński et al., 2013; Sheppard et al., 2007).

Usually the TBARS assay, and more recently isoprostanes, in particular 8-isoprostaglandin F2 $\alpha$ (8-iso-PGF2 $\alpha$ ), are considered as useful markers of free-radical lipid peroxidation (Roberts and Morrow, 2000). In the studied athletes, after the competitive phase of the annual training cycle, there was a significant increase in plasma 8-iso-prostaglandyn F2 $\alpha$ concentration (8-iso-PGF2 $\alpha$ ) (Table 5) and no change in the level of malondialdehyde measured by the thiobarbituric acid reacting substances (TBARS) assay. It is worth underlining that throughout the study period the level of both lipid peroxidation indices was kept within the range of reference values, which are $31.8 \pm 5.5$ $\mathrm{pg} \cdot \mathrm{mL}^{-1}$ for plasma 8-iso-PGF2 $\alpha$ concentration and $3.1 \pm 0.6 \mathrm{mmol} \cdot \mathrm{L}^{-1}$ for TBARS concentration in men aged 21-30 years (Roberts and Morrow, 2000; Yagi, 1987). The reason for the different actions in those two indicators remains speculative, it may as well be due to the rapid metabolic clearance.

However, Roberts and Morrow (2000) demonstrated a greater utility of the F2-IsoPs measurement compared with the TBARS.

Our data showed a significant increase in the plasma cellular damage markers $(8-\mathrm{OHdG})$ in the volleyball players after completing the main round of the competitive phase of the annual training cycle (Table 5). It should be noted that the obtained serum concentrations of 8-OHdG in both 
study terms ranged within values described by other authors in healthy subjects (between 0.8 and $38 \mathrm{ng}^{\circ} \mathrm{ml}^{-1}$ ) (Inoue et al., 2001). Such a moderate increase of the muscle damage indicators in volleyball players was observed also after an elite level game by Souglis et al. (2015). In their study volleyball players showed the smallest increase in inflammation and muscle damage markers compared with soccer, basketball and handball players. Such differences are due to many factors including the smallest mean game intensity, shortest distance covered during the game and no direct contact between the players. Results of other studies examining the effects of intensified training periods on genome stability indicate that adaptations of endogenous protective antioxidant and/or repair mechanisms prevent severe and persistent DNA damage in well-trained athletes (Miyata et al., 2008; Radák et al., 2000; Reichhold et al., 2008; Vezzoli et al., 2014). Wittwer et al. (2004) also confirmed that the activities of DNA damage-repairing enzymes were upregulated by training.

There is a wide debate in literature concerning the reliability of the serum CK level as a marker of muscle damage. Myofibrillar CK (M$\mathrm{CK})$ is bound to the M-line of the sarcoplasmic reticulum of myofibrils and is also found in the space of the I band sarcomeres providing support for muscle energy requirements (Heled et al., 2007). High CK-M activity in the blood is often used as an indirect indicator of muscle cell membrane damage. On the other hand, it has been proposed that higher than normal levels of tissue CK activity may augment the availability of cellular energy and improve myofibril contraction responses. Therefore, high levels of serum $\mathrm{CK}$, in the absence of muscle damage or other pathological conditions, may reflect the level of enzyme tissue activity of the individual (Baird et al., 2012; Brewster et al., 2006). In our study, at the end of the competitive phase, a significant decrease in CK-M activity was observed (Table 5). However, the level of serum CK-M activity remained within the reference range in the studied players throughout the study period (3.12-200 $\mu \mathrm{U} \cdot \mathrm{mL}^{-1} ;$ as recommended by CUSABIO). A lower serum CK-M activity in the analyzed players, observed after the competitive phase, may suggest reduced release from muscle tissue into the blood or an accelerated rate of $\mathrm{CK}$ clearance from the serum (Thompson et al., 2006).

The TAC value can be considered a reliable biomarker of antioxidant defense, although it should be interpreted with some caution. It is well known that oxidative stress biomarkers are influenced by sex, age, lifestyle (i.e. smoking), dietary intake, previous strenuous exercise and/or training status. To overcome this inconvenience, a "theoretically" homogeneous experimental group (males, non-smokers, young athletes) was chosen to participate in the study. In the serum of the analyzed volleyball players, the mean value of total antioxidant capacity (TAC), based on copper reducing equivalents (CRE), showed a lack of change between the two terms of the competitive phase, yet at all times remained within the reference range for the European working population (1.10-1.54 mmolCRE $\left.\mathrm{L}^{-1}\right)$ as recommended by Cell Biolabs (Table 5). However, in some human studies, chronic exercise training has been suggested to induce an increase in the capacity of the antioxidant defense systems (Elosua et al., 2003).

\section{Conclusions}

After completing the competitive phase of the annual training cycle, there was a significant increase in the cell damage indicators, such as 8iso-PGF2 $\alpha$ and 8-hydroxy-2'-deoxyguanosine. However, all the obtained values were still within the range of reference values, which may suggest that players did not cross the adaptive injury level.

No significant differences in the level of physical fitness, biochemical variables and the level of antioxidant status in the surveyed athletes between the beginning and the end of the $\mathrm{MCP}$ may indicate that the experienced cell destruction did not negatively affect physical fitness.

The data obtained in this study may be used by coaches and athletes when designing the annual training plan. They need to take into consideration that oxidative stress and inflammation may be a required physiological response for optimal adaptation to specific training loads. 


\section{References}

Ahmaidi S, Granier P, Taoutaou Z, Mercier J, Dubouchaud H, Prefaut C. Effects of active recovery on plasma Baird MF, Graham SM, Baker JS, Bickerstaff GF. Creatine-kinase- and exercise-related muscle damage implications for muscle performance and recovery. J Nutr Metab, 2012; 960363: 1-13

Brewster LM, Mairuhu G, Bindraban NR, Koopmans RP, Clark JF, van Montfrans GA. Creatine kinase activity is associated with blood pressure. Circulation, 2006; 114: 2034-2039

Brown S, Day S, Donnelly A. Indirect evidence of human skeletal muscle damage and collagen breakdown after eccentric muscle actions. J Sports Sci, 1999; 17: 397-402

Cieśla E, Dutkiewicz R, Mgłosiek M, Nowak-Starz G, Markowska M, Jasiński P, Dudek J. Sports injuries in Plus League volleyball players. J Sports Med Phys Fitness, 2015; 55: 628-38

Córdova A, Sureda A, Tur JA, Pons A. Immune response to exercise in elite sportsmen during the competitive season. J Physiol Biochem, 2010; 66: 1-6

Devita P, Skelly WA. Effect of landing stiffness on joint kinetics and energetics in the lower extremity. Med Sci Sports Exerc, 1992; 24: 108-115

Elosua R, Molina L, Fito M, Arquer A, Sanchez-Quesada JL, Covas MI, Ordoñez-Llanos J, Marrugat J. Response of oxidative stress biomarkers to a 16-week aerobic physical activity program and to acute physical activity, in healthy young men and women. Atherosclerosis, 2003; 167: 327-334

Ferretti A, Zeppilli P. Volleyball: description injuries, physiology, training. Retrieved from World Wide Web March 11

Available

at: scholar.google.pl/scholar?cluster=10216528318505609704\&hl=pl\&as_sdt=2005\&sciodt=0,5; Accessed on 5.06 .2016

González-Ravé JM, Arija A, Clemente-Suarez V. Seasonal Changes in Jump Performance and Body Composition in Women Volleyball Players. J Strength Cond Res; 2011, 25(6): 1492-1501

Heled Y, Bloom MS, Wu TJ, Stephens Q, Deuster PA. CK-MM and ACE genotypes and physiological prediction of the creatine kinase response to exercise. J Appl Physiol, 2007; 103: 504-10

Inoue T, Inoue K, Maeda H, Takayanagi K, Morooka S. Immunological response to oxidized LDL occurs in association with oxidative DNA damage independently of serum LDL concentrations in dyslipidemic patients. Clin Chim Acta, 2001; 305: 115-121

Lehnert M, Sigmund M, Lipinska P, Varekova R, Hroch M, Xaverova Z, Stastny P, Hap P, Zmijewski P. Training-induced changes in physical performance can be achieved without body mass reduction after eight week of strength and injury prevention oriented programme in volleyball female players. Biol Sport. 2017; 34(2): 205-213

Manna I, Khanna GL, Dhara PC. Effect of Training on Anthropometric, Physiological, and Health-Related Variables of Indian Senior Elite Volleyball Players. Asian J Exerc Sports Sci, 2011; 8(1): 64-82

Maughan RJ. A simple, rapid method for the determination of glucose, lactate, pyruvate, alanine, 3hydroxybutyrate and acetoacetate on a single 20-mul blood sample. Clin Chim Acta, 1982; 122: 231-240

Miyama M, Nosaka K. Influence of surface on muscle damage and soreness induced by consecutive drop jumps. J Strength Cond Res, 2004; 18: 206-211

Miyata M, Kasai H, Kawai K, Yamada N, Tokudome M, Ichikawa H, Goto C, Tokudome Y, Kuriki K, Hoshino H, Shibata K, Suzuki S, Kobayashi M, Goto H, Ikeda M, Otsuka T, Tokudome S. Changes of urinary 8-hydroxydeoxyguanosine levels during a two-day ultramarathon race period in Japanese non-professional runners. Int J Sports Med, 2008; 29: 27-33

Nikolaidis MG, Jamurtas AZ, Paschalis V, Fatouros IG, Koutedakis Y, Kouretas D. The effect of muscledamaging exercise on blood and skeletal muscle oxidative stress: magnitude and time-course considerations. Sports Med, 2008; 38: 579-606

Obmiński Z, Lerczak K, Witek K. The effect of repeated volleyball matches on the morning plasma levels of hormones, metabolites and muscle and liver enzymes in male volleyball players. Polish J Sport Med, 2013; 29(1): 37-43

Podgórski T, Adrian J, Nowak A. Changes in lactate, pyruvate and glucose levels in field hockey players under different training and match stimuli. TSS, 2015; 3(22): 145-152 
Polglaze T, Dawson B. The physiological requirements of the positions in state league volleyball. Sports Coach, 1992; 15: 32-37

Radák Z, Pucsuk J, Boros S, Josfai L, Taylor AW. Changes in urine 8-hydroxydeoxyguanosine levels of super-marathon runners during a four-day race period. Life Sci, 2000; 66: 1763-1767

Rankovic G, Mutavdzic V, Toskic D, Preljevic A, Kocic M, Nedin Rankovic G, Damjanovic Aerobic capacity as an indicator in different kinds of sports. N.Bosn J Basic Med Sci, 2010; 10(1): 44-8

Reichhold S, Neubauer O, Ehrlich V, Knasmüller S, Wagner KH. No acute and persistent DNA damage after an Ironman triathlon. Cancer Epidemiol, Biomarkers Prev, 2008; 17: 1913-1919

Roberts LJ, Morrow JD. Measurement of F2-isoprostanes as an index of oxidative stress in vivo. Free Radic Biol Med, 2000; 28: 505-513

Sheppard J, Cowan E. Long-term Training Adaptations in Elite Male Volleyball Players University Robert Newton Edith Cowan University, 2011. Available at: http://ro.ecu.edu.au/cgi/viewcontent.cgi?article=1845\&context=ecuworks2011; Accessed on 24.05.2016

Sheppard JM, Gabbett T, Taylor KL, Dorman J, Lebedew AJ, Borgeaud R. Development of a repeated-effort test for elite men's volleyball. Int J Sports Physiol Perform, 2007; 2: 292-304

Smith DJ, Roberts D, Watson B. Physical, physiological and performance differences between Canadian national team and universiade volleyball players. J Sports Sci, 1992; 10(2): 131-138

Smith LL. Cytokine hypothesis of overtraining: a physiological adaptation to excessive stress. Med Sci Sports Exerc, 2000; 32: 317-331

Souglis A, Bogdanis GC, Giannopoulou I, Papadopoulos Ch, Apostolidis N. Comparison of inflammatory responses and muscle damage indices following a soccer, basketball, volleyball and handball game at an elite competitive level. Res Sports Med, 2015; 23(1): 59-72

Thompson HS, Scordilis SP, De Souza MJ. Serum creatine kinase activity varies with ovulatory status in regularly exercising, premenopausal women. Horm Res, 2006; 65: 151-158

Vezzoli A, Pugliese L, Marzorati M, Serpiello FR, La Torre A, Porcelli S. Time-course changes of oxidative stress response to high-intensity discontinuous training versus moderate-intensity continuous training in masters runners. PLoS One, 2014; 9: 1-9

Witek K. Changes in serum lipid profile of elite volleyball players in the competition period. Biomed Hum Kinetics, 2009; 1: 63-66

Wittwer M, Billeter R, Hoppeler H, Flück M. Regulatory gene expression in skeletal muscle of highly endurance trained humans. Acta Physiol Scand, 2004; 180: 217-227

Yagi K. Lipid peroxides and human disease. Chem Phys Lipids. 1987; 45: 337-351

\section{Corresponding author:}

\section{Karolkiewicz Joanna}

Department of Hygiene, University School of Physical Education

ul. Królowej Jadwigi 27/39

61-871 Poznań, Poland

Tel +48 618355170

Email: karolkiewicz@awf.poznan.pl 